\title{
Insight into biological phosphate recovery from sewage
}

\author{
Yuanyao Ye $e^{\mathrm{a}}$, Huu Hao Ngo ${ }^{\mathrm{a}, \mathrm{b}^{*}}$, Wenshan Guo ${ }^{\mathrm{a}}$, Yiwen Liu ${ }^{\mathrm{a}}$, Xinbo Zhang ${ }^{\mathrm{b}}$, Jianbo Guo ${ }^{\mathrm{b}}$, \\ Bing-jie, Nic, Soon Woong Chang ${ }^{d}$, Dinh Duc Nguyen ${ }^{d}$ \\ ${ }^{a}$ Centre for Technology in Water and Wastewater, School of Civil and Environmental Engineering, \\ University of Technology Sydney, Sydney, NWS 2007, Australia \\ ${ }^{b}$ Department of Environmental and Municipal Engineering, Tianjin Chengjian University, Jinjing Road \\ 26, Tianjin 300384, China. \\ ${ }^{c}$ State Key Laboratory of Pollution Control and Resources Reuse, College of Environmental Science and \\ Engineering, Tongji University, Shanghai 200092, PR China \\ ${ }^{d}$ Department of Environmental Energy and Engineering, Kyonggi University, 442-760, Republic of Korea
}

\begin{abstract}
The world's increasing population means that more food production is required. A more sustainable supply of fertilizers mainly consisting of phosphate is needed. Due to the rising consumption of scarce resources and limited natural supply of phosphate, the recovery of phosphate and their re-use has potentially high market value. Sewage has high potential to recover a large amount of phosphate in a circular economy approach. This paper focuses on utilization of biological process integrated with various subsequent processes to concentrate and recycle phosphate which are derived from liquid and sludge phases. The phosphate accumulation and recovery are discussed in terms of mechanism and governing parameters, recovery efficiency, application at plant-scale and economy.
\end{abstract}

Keywords: phosphate recovery, biological process, anaerobic digester supernatant, sewage sludge, sewage 


\section{Introduction}

Phosphate is essential for the growth of photosynthetic organisms as they can provide organisms with energy and vital elements. However, excessive concentrations of phosphate cause eutrophication which reduces the quality of aquatic environment and even poses a risk to aquatic communities and human life. Most of phosphate in wastewater is derived from domestic, industrial and agricultural sources (Pratt et al., 2012). Additionally, the increasing demand for global food production in turn requires rising production of fertilizers to ensure the development of agricultural products. Moreover, phosphorus is a non-renewable resource and its global supply will all be consumed in 200 years (Huang et al., 2014). Thus, removing phosphate from sewage and its recovery can inhibit eutrophication to occur and also be a supplementary source for fertilizers production in agriculture. As sewage sludge is mainly disposed by incineration or landfill and both of the methods may somewhat impair the environment, recovering phosphate from sewage can minimize the production of sewage sludge and the detrimental effects of the disposal of sewage sludge on environment thereby reduce. Sewage has the highest potential to recover $\mathrm{PO}_{4}{ }^{3-}-\mathrm{P}$ because the entire amount of recovered phosphate from municipal wastewater could theoretically accounts for $15-20 \%$ of the global phosphorus demand (Yuan et al., 2012). For this reason, the phosphate recovery has high priority in sewage treatment.

Currently, the biological process for phosphate removal (e.g. Enhanced Biological Phosphorus Removal, EBPR) is more attractive despite chemical phosphate removal (e.g. chemical precipitation) used more widely (Verstraete et al., 2009). EBPR system has been utilized for phosphate recovery as it could concentrate phosphate both in liquid (e.g. anaerobic digester supernatant) and solid phases (e.g. sewage sludge/ash) (Tarayre 
et al., 2016; Xie et al., 2011). In fact, the phosphorus concentration in sewage is low (< $10 \mathrm{mg} / \mathrm{L}$ ) while phosphate recovery and reuse are more feasible with rich phosphate in a wastewater stream (Geerts et al., 2015). To overcome this difficulty, EBPR system shows its high potential to recover phosphate from sewage. For instance, EBPR can be applied to different sewage sources containing $20-100 \mathrm{mg} / \mathrm{L}$ of phosphorus with over $90 \%$ of phosphorus removed (Mulkerrins et al., 2004).

The potential locations for biological phosphate recovery are summarized in Figure 1. Through anaerobic digestion, the organic substances in municipal wastewater and sewage sludge can be decomposed with simultaneous production of soluble phosphate. As such, anaerobic digestion supernatant (A), reject water (B) and sludge dewatering filtrate (C) contain high concentrations of phosphate as the liquid sources for phosphate recovery. Dry surplus sludge (SS) (1) and sewage sludge ash (SSA) (2) have been used previously for direct land application as the fertilizers. However, they were banned in some European counties such as Switzerland (Schoumans et al., 2015) because they contained heavy metals, pathogens and toxic substances. SS is incinerated to achieve SSA without organic matter retained. Although most heavy metals are enriched in SSA, mercury is evaporated due to its low boiling point (Lederer and Rechberger, 2010). The big challenges for recovering phosphate from the potential sources are to find the way to reduce the disturbance caused by foreign ions and separate recovered phosphate from heavy metals and toxic substances. Nevertheless, biological process integrated with innovative subsequent processes could lead to an efficient and effective system for phosphate recovery.

\section{Figure 1}


Even though some reviews have discussed biological phosphate recovery from sewage, to our knowledge, most of them focus on the general information without detailed comparison. Hence, this article presents a comprehensive review on biological phosphate recovery integrated with subsequent process from sewage towards developing a better phosphate recovery process for more effective process design in sewage treatment plants. The application at plant-scale, mechanism and governing parameters of the phosphate recovery are also discussed.

\section{Biological phosphate recovery in sewage treatment}

\subsection{Mechanism}

Fig. 2 demonstrates the mechanism of biological process for phosphate recovery (Wong et al., 2013). Generally, the biological phosphorus recovery includes phosphate release under anaerobic conditions and subsequent phosphate uptake and storage in the activated sludge in the form of intracellular polyphosphate under aerobic conditions.

\section{Figure 2}

Anaerobically, polyphosphate is hydrolyzed and then releases phosphate from the cell as well as the relevant metal ions such as $\mathrm{Mg}^{2+}$ and $\mathrm{K}^{+}$, causing the increase in the residual concentrations of $\mathrm{P}$ in wastewater. This process could generate energy for the carbon sources (mainly the volatile fatty acids (VFAs)) uptake and intracellular storage in the form of poly- $\beta$-hydroxyalkanoates (PHAs) by polyphosphorus accumulating organisms (PAOs) (Ye et al., 2013; Zeng et al., 2011). The formation of PHAs needs reducing power which is mainly derived from the glycolysis of internally stored glycogen (Mino et al., 1998; Tayà et al., 2011). It is worth noting that the oxidation of VFAs can support the partial reducing power via the tricarboxylic acid (TCA) cycle (Zhou et al., 2010). The anaerobic metabolism of PAOs has its enormous advantages 
compared to the ordinary heterotrophic organisms (OHOs). This may be attributed to the absence of external electron acceptors for OHOs to utilize the carbon sources in this scenario (Yuan et al., 2012). Subsequently, PAOs can utilize their previously stored PHAs as the energy source to promote cell growth, replenish glycogen, take up and store phosphate as polyphosphate incorporated into the biomass under aerobic microenvironment. In this scenario, PAOs may have luxury uptake as the amount of phosphate uptake is more than the biomass growth requirement while surplus sludge containing phosphate is discharged for the achievement of phosphate recovery (Zhang et al., 2011). The metal ions such as $\mathrm{Mg}^{2+}$ and $\mathrm{K}^{+}$are also taken up by PAOs, and concentrated and incorporated into the sludge biomass (Yuan et al., 2012). Additionally, some PAOs can use nitrate or nitrite as the electronic acceptor instead of oxygen to take up P under anoxic conditions with denitrification occurring simultaneously (Frison et al., 2015; Wang et al., 2015). This scenario could also produce active sludge containing rich phosphate with simultaneous removal of nitrogen.

\subsection{Operating parameters}

Glycogen accumulating organisms (GAOs) may compete with PAOs for carbon sources under alternating anaerobic and aerobic/anoxic conditions for their proliferation (Zhang et al., 2011). However, GAOs may not contribute to the phosphate release and uptake so as the existence of GAOs may inhibit the phosphate release and uptake by PAOs and thus reduce the efficiency of phosphate recovery. The parameters including temperature and $\mathrm{pH}$ may affect the competition between PAOs and GAOs in the phosphate recovery process (Zuthi et al., 2013). The main operating parameters are summarized in Table 1.

\section{Table 1}




\subsubsection{Temperature}

Temperature affects both the metabolic activities of the microorganisms and their diversity (Li et al., 2010). Ong et al. (2014) reported that superior phosphorus removal efficiency could be achieved at high temperatures $\left(24,28\right.$ and $\left.32{ }^{\circ} \mathrm{C}\right)$. Moreover, the enhanced phosphate removal efficiency has been observed at higher temperature with other typical biological reactions (Baetens et al., 1999; Brdjanovic et al., 1998). In these studies, the optimized temperature for the phosphate removal ranges from 24 to $37^{\circ} \mathrm{C}$ and phosphate removal was inhibited at temperatures below $20^{\circ} \mathrm{C}$. However, Bassin et al. (2012) found that the phosphorus removal efficiency was greater than $90 \%$ at $20{ }^{\circ} \mathrm{C}$ compared to $60 \%$ at $30{ }^{\circ} \mathrm{C}$ in the lab-scale SBR system. Apart from this, the effects of temperature $\left(10-40{ }^{\circ} \mathrm{C}\right)$ on the competition between PAOs and GAOs in anaerobic and aerobic environment revealed that the carbon source favours GAOs at high temperature $\left(>20^{\circ} \mathrm{C}\right)$ so as phosphate removal is inhibited at this temperature range

(Lopez-Vazquez et al., 2007). The possible reason for this is glycogen transformation at lower temperatures may prefer PAOs to GAOs. As phosphate removal is inhibited in summer but better during winter at plant-scale (Gebremariam et al., 2011), colder temperature facilitates phosphate removal/recovery. Moreover, Wang and Chen (2015) also recently stated that $5.44 \times 10^{2} \mathrm{~kg} /$ day of phosphorus removed in winter compared with $3.92 \times 10^{2} \mathrm{~kg} /$ day of $\mathrm{P}$ removed in summer at a full-scale plant. For this reason, Zheng et al. (2014) concluded that PAOs and GAOs are psychrophiles and mesophiles, respectively.

\subsection{2 $\mathrm{pH}$}

Basically, organisms need more energy for substrate uptake at high $\mathrm{pH}$ and PAOs have more energy sources compared to GAOs. Thus, high $\mathrm{pH}$ could enhance phosphate 
removal/recovery efficiency (Gebremariam et al., 2011). Wang et al. (2013) showed that the phosphate removal efficiency was higher at initial $\mathrm{pH} 7.8$ than that at initial $\mathrm{pH}$ 6.6 in the aerobic/extended-idle (AEI) regime of SBR system. Simultaneously, more PAOs are observed at initial $\mathrm{pH} 7.8$ compared with those at initial $\mathrm{pH}$ 6.6. However, some studies also indicated that the value of $\mathrm{pH}$ tends to be around 7.0 in EBPR system regardless of the initial pH (Liu et al., 2007). Similarly, Gu et al. (2008) evaluated the full-scale EBPR plants under the $\mathrm{pH}$ ranges from 7.2 (anaerobic microenvironment) to 8.3 (aerobic microenvironment) and found that there was no association between $\mathrm{pH}$ and phosphorus removal and process stability. Thus, the effects of $\mathrm{pH}$ on competition between PAOs and GAOs have not been definitively established and more studies are needed.

\subsubsection{Carbon availability and type}

In wastewater treatment, chemical oxygen demand (COD) can mostly reflect the carbon. $90 \%$ of phosphate removed in the EBPR process is observed at the COD/P range of 18-20 (Chuang et al., 2011). The microorganisms in the biological systems need carbon for synthesizing, accumulating and storing products so that the type and availability of carbon is important for the phosphate removal/recovery (Yu et al., 2014). VFAs are the main carbon source for phosphate release and uptake by PAOs (Yuan et al., 2012) and Zhang et al. (2011) believed that high VFAs level contributes to the low concentration of phosphate in the effluent and thus facilitates to the phosphate recovery.

Additionally, Gebremariam et al. (2012) studied the effects of adding glucose to phosphate removal in EBPR system. They indicated that equal parts of glucose and acetate could improve the performance while EBPR system was inhibited with glucose as the only carbon source (Zengin et al., 2010). Similarly, when acetate was used as the 
only substrate, the efficiency of phosphate removal was not satisfactory (Chuang et al., 2011; Gebremariam et al., 2012). It was reported that the simultaneous presence of acetate and propionate as carbon sources (e.g. $75-25$ or $50-50 \%$ acetate to propionate ratios) favours PAOs over to GAOs, regardless of $\mathrm{pH}$, while the sole presence of acetate or propionate as the carbon source only favours PAOs over GAOs at a high $\mathrm{pH}$ (7.5) (Lopez-Vazquez et al., 2009). Moreover, Wang et al. (2010) found that acetate as a sole carbon source could improve phosphate release better than propionate. However, the higher efficiency of phosphate recovery is observed while use of propionate as the sole carbon source (Hood and Randall, 2001).

\subsubsection{Dissolved oxygen (DO)}

Low DO concentration can contribute to high phosphate removal/recovery efficiency since the proliferation of GAOs is reduced at such low DO levels (Winkler et al., 2011). Thus, more carbon sources could be utilized to the proliferation of PAOs and due to this, the phosphate uptake by PAOs is improved. The effect of DO on phosphate removal was studied in the aerobic/extended-idle (A/EI) regime of the SBR system after operating for approximately $21 \mathrm{~d}$ (Chen et al., 2014). In this study, the phosphate removal is highly dependent on the concentration of DO and better efficiency of phosphorus removal (around 98.5\%) is shown at low DO concentration ( $1 \mathrm{mg} / \mathrm{L}) . \mathrm{In}$ addition, the low DO level could accelerate the phosphate uptake and release rates.

Carvalheira et al. (2014) also found that the decrease in the DO level enables PAOs to have advantages over GAOs because oxygen has comparatively better affinity for PAOs than GAOs at low DO concentration. 


\section{Comparison of biological phosphate recovery from the liquid and sludge phase}

In normal sewage treatment, Cornel and Schaum (2009) found that approximately $11 \%$ of total phosphorus in influent is incorporated into the primary sludge while around $28 \%$ of incoming phosphorus load can be removed only through biological sewage treatment in the form of phosphorus-rich biomass with the discharge of surplus sludge. Thus, at least approximately $40 \%$ of incoming phosphorus load can be concentrated in the sewage sludge in the absence of EBPR system. In EBPR system, the content of phosphate in the surplus sludge can be enhanced (Yuan et al., 2012). However, partial of incoming phosphorus load is still concentrated in the liquid phase through PAOs. As $90 \%$ of total phosphorus can be removed in sewage treatment (Tarayre et al., 2016), EBPR system can combine with chemical precipitation, adsorption, membrane hybrid system or other processes to achieve the residuary $50 \%$ of total phosphorus load removal (Henze et al., 2008). For biological phosphate recovery from the sludge phase, phosphate bound in the sludge phase can alternatively be converted into water-soluble form and then recovered. In addition, the popular solutions for phosphate recovery from the liquid phase mainly include $\mathrm{Mg}(\mathrm{OH})_{2}, \mathrm{Ca}(\mathrm{OH})_{2}$, $\mathrm{MgCl}_{2}$ integrated with $\mathrm{NaOH}$ and $\mathrm{CaCl}_{2}$ integrated with $\mathrm{NaOH}$.

\subsection{Membrane Technology}

In biological phosphate recovery process, membrane technology can be integrated with the biological wastewater treatment process to recovery phosphate directly and indirectly with high efficiency and purity from the liquid phase (Marbelia et al., 2014;

Qiu et al., 2015; Zhang et al., 2014). Qiu and Ting (2014a) recently reported that an osmotic membrane bioreactor (OMBR) which is obtained through biological sewage treatment process integrated with forward osmosis (FO) can directly recover phosphate 
within the bioreactor. The organic substances and part of nitrogen is also removed by biological metabolism in the bioreactor. Due to a high-rejection rate, $\mathrm{Ca}^{2+}, \mathrm{Mg}^{2+}, \mathrm{NH}_{4}{ }^{+}$ and $\mathrm{PO}_{4}{ }^{3-}$ ions are rejected and concentrated within the bioreactor. Therefore, there is no need to add $\mathrm{Ca}^{2+}, \mathrm{Mg}^{2+}$ and $\mathrm{NH}_{4}{ }^{+}$ions for phosphate recovery via chemical precipitation within the bioreactor. Based on the OMBR system, Qiu et al. (2015) added the microfiltration membrane (MF) to directly recover phosphate with higher purity. In the MF-OMBR system, FO rejects the phosphates while MF extracts the phosphate-rich supernatant in the bioreactor. Similarly, reverse osmosis can also be combined with OMBR for both recovering phosphate and producing clean water (Luo et al., 2016). Further, salt accumulation and membrane fouling could also both be moderated within the MBR systems discussed above, which contributes to the better performance of membrane and microbiological growth, thus enhancing the efficiency of phosphate recovery. The possible reasons for the low membrane fouling are: a) the typical properties of FO membranes such as the smooth and hydrophilic nature and the relatively low water flux compared with that in traditional MBR systems can result in low membrane fouling in OMBR (Yap et al., 2012); b) osmotic backwashing is utilized for the foulants removal from the membrane surface (Achilli et al., 2009); c) FO can reject a wide range of contaminants and mineral salts, resulting in reduction in membrane fouling of downstream RO (Qiu and Ting, 2014b); and d) the use of osmotic pressure in OMBR system can cause the lower fouling potential compared with that of hydraulic pressure (Achilli et al., 2009; Cornelissen et al., 2008). Moreover, soluble salts can be discharged through MF to alleviate the salt accumulation in OMBR system (Wang et al., 2014). 
Microbial fuel cells (MFC) can be used to recover phosphate from both liquid and sludge phases (Cusick and Logan, 2012; Fischer et al., 2011; Hirooka and Ichihashi, 2013). Ichihashi and Hirooka (2012) used air-cathode MFCs to treat swine wastewater, resulting in $27 \%$ of phosphorus recovered through struvite. The possible for this is the value of $\mathrm{pH}$ near the cathode increases due to the accumulation of hydroxide caused by the depletion of proton and fluent alkali cations during oxygen reduction reaction (Zhao et al., 2006). Hence, soluble phosphate can be precipitated with added magnesium and ammonia at high $\mathrm{pH}$ and struvite is formed. As the precipitation does not need to adjust $\mathrm{pH}$, the use of MFC seems to be more economical than the conventional struvite precipitation due to reduction in consumption of chemicals for increasing $\mathrm{pH}$ (Jaffer et al., 2002). Further, Tao et al. (2014) utilized a two-chamber MFC for phosphate recovery from synthetic wastewater and then found that approximately $80 \%$ of total phosphates can be removed via chemical precipitation while microbial community adsorbs about $4-17 \%$ of incoming phosphorus load. In this study, they observed that MFC can be applied to wastewater treatment under ambient conditions with small size of equipment so as it is economically utilized at small-scale plant. Moreover, MFC can reduce the production of sludge with quick launch the wastewater (Tao et al., 2014). However, the accumulation of recovered phosphate (i.e. struvite) is observed on the surface of the cathode and thus this may inhibit the cathode's performance. Similarly, microbial electrolysis cell (MEC) as another type of electrolysis system has been conducted for phosphate recovery from wastewater with $40 \%$ of phosphorus recovered (Cusick and Logan, 2012).

Besides, Fischer et al. (2011) utilized MFC for biological phosphate recovery from the sludge phase because it can release phosphate from digested sewage sludge to the 
liquid phase. The supernatant containing insoluble phosphate is then mixed with the addition of $\mathrm{Mg}^{2+}$ and $\mathrm{NH}_{4}{ }^{+}$with simultaneous adjustment of $\mathrm{pH}$, leading to the formation of struvite. The use of MFC is to transfer electrons and protons as a power source, which causes the reduction in insoluble phosphate and thereby forms more phosphate dissolved in the supernatant.

In addition, bioleaching has been used to extract phosphate from rock phosphate because inorganic acids produced by some microorganisms can solubilize the insoluble phosphate bound in the rock (Sarlin et al., 2013). Chi et al. (2006) utilized the bacterium Acidithiobacillus ferrooxidans (At. f.) which can produce sulphuric acid to release phosphate from rock phosphate despite of low leach efficiency of phosphate (11.8\%). Based on this foundation, P-bac ${ }^{\circledR}$ process utilizes sulphuric acid derived from the proliferation of the specific microorganisms to extract phosphorus and heavy metals from SSA (P-bac, 2013) and achieved biomass containing rich phosphorus with $90 \%$ of total phosphorus recovered. However, information about the final product in this process is unavailable.

In conclusion, biological phosphate recovery from the sludge phase is more complicated due to the complex composition of sewage sludge (ash), compared to that from the liquid phase. Although phosphate recovery from the liquid phase may require some special facilities to achieve P recovery, biological phosphate recovery from the sludge phase may require fermentation of the sewage sludge and acid-resistant equipment and thereby it is not economical at a small plant-scale. Moreover, SSA is achieved through incineration of SS, thus recovering phosphate from that will cost much more than from other sources, which limit its application as a fertilizer source. Some by-products such as soluble (heavy) metals and acidic sludge may be produced in 
the phosphate recovery process from the sludge phase. However, this needs subsequent processing to reduce their risks to environment.

\subsection{Application at plant-scale}

EBPR system integrated with other process can create an effective system for phosphate recovery with high efficiency and purity (Shi et al., 2012; Tarayre et al., 2016; Yan et al., 2015; Zou and Wang, 2016). In this study, inorganic solids separation, phosphorus recovery, and enhanced phosphate removal (SIPER) system are discussed which is part of the current phosphate recovery method (Fig. 3) (Yan et al., 2013).

\section{Figure 3}

The biological nutrient removal (BNR) system (i) utilizes microbial metabolism, which aims at: a) decomposing organics; and b) removing toxic substances, heavy metals and phosphate while (ii) represents a side-stream enhanced sludge hydrolysis and acidification system which results in the reduction and solubilization of the sludge by cell destruction. This is followed by returning the treated sludge to the BNR system as a carbon source to improve biological performance. The side-stream inorganic solids separation system (iii) selectively separates the inorganic or inert solids from the sludge to avoid their accumulation in the sludge reduction process. For (iv), the side-stream phosphorus recovery system, phosphate are recovered as crystals from anaerobically digested supernatant containing rich phosphate. The cyclic activated sludge system (CASS) is used in the process and about $74.5 \%$ of phosphorus can be recovered as struvite.

Currently, the disposal of surplus sludge may increase the operational costs of wastewater treatment plants and also be potentially risky to the environment because of the sludge containing toxic substances (Tian et al., 2012; Wang et al., 2011a; Xie et al., 
2013). The surplus sludge can be utilized as a potential source for phosphate recovery; however, further processing is required with additional equipment, depletion of chemicals and/or energy which cause additional costs. Moreover, due to the limited amount of carbon source in wastewater (Hao et al., 2013; Zeng et al., 2013) and stringent requirement effluent concentrations of phosphate (Anzecc, 2000; Shepherd et al., 2016), the external carbon source should be added to wastewater treatment to enhance phosphate removal/recovery efficiency. Obviously, the addition of carbon sources may put a great burden on sewage plants. In the SIPER system, the sludge produced in the BNR system is utilized to be supplementary carbon sources after being treated. This can reduce the sludge production and save the operational costs with simultaneous enhancement of denitrification for nitrogen removal. Besides, phosphate removal/recovery is achieved through the discharge of surplus sludge in the conventional biological phosphate removal/recovery system. Thus, high efficiency of phosphate removal/recovery needs considerable amount of discharge of surplus sludge. For this reason, the good performance of phosphate removal/recovery cannot be obtained with simultaneous reduction in surplus sludge. However, in the SIPER system most of incoming phosphate load is recovered via struvite crystallization which can be utilized as a fertilizer and the residual phosphate is removed with the discharge of surplus sludge. Hence, the phosphate removal/recovery is independent on the amount of the discharge of surplus sludge with simultaneous reduction in surplus sludge. The internal cycle of treated sewage sludge as the carbon sources and reduction in the production of surplus sludge can both decrease the costs of the SIPER system. This is despite the fact that the system may still deplete a lot of chemicals for phosphate 
recovery due to the formation of struvite and the complexity of the technology may somewhat affect the phosphate recovery efficiency and thereby inhibit its application.

P-bac ${ }^{\circledR}$ process developed by Fritzmeier Umwelttechnik and the Institute of Hygiene and Environmental Medicine RWTH Aachen seeks to selectively recover phosphate from SSA through biotechnology (P-bac, 2013). P-bac ${ }^{\circledR}$ process for selective phosphate recovery consists of two steps. Firstly, sulphuric acid produced by microbial proliferation is utilized to release phosphate and heavy metals bound in SSA to the liquid phase within few hours. The mixture is subsequently conducted through solid-liquid separation to achieve the residue which needs further disposal and the supernatant containing rich phosphate and heavy metals. It is worth noting that this step can be also applied in the mining industry to exploit heavy metals such as $\mathrm{Cu}$ and $\mathrm{Zn}$. Secondly, the biomass which takes up phosphate is separated from the supernatant/heavy metals and then processed, thus achieving selective phosphate recovery. Further, the residuary heavy metals are chemically processed and concentrated. According to P-bac ${ }^{\circledR}$ process, the recovery efficiency of total phosphorus is up to $90 \%$ while high content of heavy metals of solid can also be achieved. P-bac ${ }^{\circledR}$ process needs common operational environment such as low temperature and atmospheric pressure. In addition, this process reduces the depletion of chemicals, but it is highly dependent on microbial activity, thus biological stability and reliability may affect the successful application of P-bac ${ }^{\circledR}$ process at plant-scale. A solid containing high concentration of heavy metals can also be obtained from this process.

\subsection{Economy}


Phosphate recovery from the sludge phase is more costly in comparison to that from the liquid phase because: (i) it needs to release phosphate bound in SS/SSA to the liquid phase or to increase the bioavailability of insoluble phosphate, thus more equipment, downstream process and/or energy is required; and (ii) generates by-products which need further disposal and thereby increase the operational costs (Liu and Qu, 2016; Montag et al., 2009; Sartorius et al., 2012; Tarayre et al., 2016). However, the high costs of membrane may inhibit the application of MBR for biological phosphate recovery while the accumulation of struvite on the cathode's surface may affect the performance of MFC in the biological phosphate recovery from the liquid phase. Furthermore, methane gas produced in the sewage treatment process can be utilized to generate energy for biological phosphate recovery if necessary.

During the biological phosphate recovery process, the energy is needed for the system's sustainability and renewable energy could be utilized to save costs. The price of recovered phosphate is not only highly dependent on product quality and market demand, but also related to the policy. Although phosphate recovery from sewage is not yet economically feasible compared with rock phosphate while application as a fertilizer (Molinos-Senante et al., 2011), it is still significant to develop phosphate recovery system due to their increasing depletion. Nevertheless, recovering phosphate from sewage could not only effectively relieve the burden of increasing depletion of phosphorus sources, but also contribute to the disposal of heavy metals. The phosphate recovery could also enhance the dewaterability of the treated sludge and decrease the scaling speed, which reduces the operational problems such as pipe clogging and valve freezing at a full scale pilot study (Marchi et al., 2015). 


\section{Future perspectives}

As mentioned above, the economic feasibility of phosphate recovery from sewage could only be achieved when the concentration of phosphorus is more than $50 \mathrm{mg} / \mathrm{L}$ in the influent (Geerts et al., 2015) while the concentration of phosphorus in sewage is less than $10 \mathrm{mg} / \mathrm{L}$. Thus, EBPR system shows considerable advantages in recovering phosphorus from sewage as it can concentrate phosphate in the liquid and sludge phase. However, this system cannot achieve good performance on removal of carbon and nitrogen. For this reason, its application should be considered on a case-by-case basis. Nevertheless, the successful application of biological phosphate recovery from sewage can still recover phosphate with high purity and benefit the operation of sewage treatment (e.g. reduction in the flow back of phosphate with digester supernatant and operational costs due to avoiding the occur of incrustations). Basically, the successful application of biological phosphate recovery is highly dependent on the changes in concentrations of phosphate influent (Wang et al., 2011b) and the activities of PAOs under althernative anaerobic and anoxic/aerobic microenvironemnt. Moreover, the sufficient carbon sources are quite important for biological phosphate recovery due to theirs providing the energy for metabolism. As the carbon sources are normally limited (Hu et al., 2011; Naessens et al., 2012), high efficiency of biological phosphate recovery should be achieved through the design and operation of sewage treatment plants. After solving the challenges mentioned above, the efficient and effective EBPR system for phosphate recovery can be much more accessible. In addition, further studies on the performance of biological phosphate recovery and analysis of their recovery efficiency and quality of recovered phosphate from different phases are essential. This will contribute to a positive effect on developing the market of recovered phosphate. Based 
on the legislative framework of contaminants and eco-toxcity, analysis on the properties of recovered phosphates is also important to assess their potential in agriculture as well as economic feasibility (Kataki et al., 2016). The high costs of phosphate recovery including processing, transportation and distribution may inhibit the application of recovered phosphate as a fertilizer as the conventional fertilizer is more economical. Hence, more studies should be conducted to reduce the cost of phosphate recovery and reuse to make the application of recovered phosphate more economic feasibility. For example, seawater which consists of abundant $\mathrm{Mg}$ could be utilized as the $\mathrm{Mg}$ source for biological phosphate recovery integrated with struvite while renewable energy such as solar energy could be used for sustainability and operation of the system. Both of these methods could decrease the cost of phosphate recovery whilst enhancing the development of other industries. It is worth to noting that the climatic and edaphic factors could also influence the application in terms of outcomes. As such, the application of recovered phosphates needs more systematic research to enhance the market development of recovered phosphate.

\section{Conclusion}

Through recovering the limited deposits of phosphorus, effects of sewage discharge on environment can be minimized while supplementary source for phosphorus can be generated. The biological phosphate recovery from sewage is highlighted because it can enable phosphate enrichment from the high quality of wastewater. Although the stability and reliability of the biological process are challenges for phosphate recovery and low content of phosphorus in sewage, the potential application remains. Consequently, further study on the current problems inherent in biological phosphate recovery process is necessary. 


\section{Acknowledgments}

This review research was supported by the Centre for Technology in Water and

Wastewater, School of Civil and Environmental Engineering, University of Technology,

Sydney (UTS). The authors are grateful to the research collaboration among UTS,

Tianjin Chengjian University, Tongji University and Kyonggi University.

\section{Reference}

1. Achilli, A., Cath, T.Y., Marchand, E.A., Childress, A.E. 2009. The forward osmosis membrane bioreactor: a low fouling alternative to MBR processes. Desalination, 239(1), 10-21.

2. Anzecc, A. 2000. Australian and New Zealand Guidelines for Fresh and Marine Water Quality. I. The Guidelines. Department of the Environment, 1, 1-103.

3. Baetens, D., Vanrolleghem, P., Van Loosdrecht, M., Hosten, L. 1999. Temperature effects in bio-P removal. Water Science and Technology, 39(1), 215-225.

4. Bassin, J., Winkler, M.K., Kleerebezem, R., Dezotti, M., Van Loosdrecht, M. 2012. Improved phosphate removal by selective sludge discharge in aerobic granular sludge reactors. Biotechnology and Bioengineering, 109(8), 1919-1928.

5. Brdjanovic, D., Logemann, S., Van Loosdrecht, M.C., Hooijmans, C.M., Alaerts, G.J., Heijnen, J.J. 1998. Influence of temperature on biological phosphorus 
removal: process and molecular ecological studies. Water Research, 32(4), $1035-1048$.

6. Carvalheira, M., Oehmen, A., Carvalho, G., Eusébio, M., Reis, M.A. 2014. The impact of aeration on the competition between polyphosphate accumulating organisms and glycogen accumulating organisms. Water Research, 66, 296-307.

7. Chen, H., Wang, D., Li, X., Yang, Q., Luo, K., Zeng, G., Tang, M., Xiong, W., Yang, G. 2014. Effect of dissolved oxygen on biological phosphorus removal induced by aerobic/extended-idle regime. Biochemical Engineering Journal, 90, $27-35$.

8. Chi, R.-a., Xiao, C.-q., Gao, H. 2006. Bioleaching of phosphorus from rock phosphate containing pyrites by Acidithiobacillus ferrooxidans. Minerals Engineering, 19(9), 979-981.

9. Chuang, S.H., Chang, W.C., Huang, Y.H., Tseng, C.C., Tai, C.C. 2011. Effects of different carbon supplements on phosphorus removal in low $\mathrm{C} / \mathrm{P}$ ratio industrial wastewater. Bioresource Technology, 102(9), 5461-5465.

10. Cornel, P., Schaum, C. 2009. Phosphorus recovery from wastewater: needs, technologies and costs. Water Science and Technology, 59(6).

11. Cornelissen, E., Harmsen, D., De Korte, K., Ruiken, C., Qin, J.-J., Oo, H., Wessels, L. 2008. Membrane fouling and process performance of forward osmosis membranes on activated sludge. Journal of Membrane Science, 319(1), $158-168$. 
12. Cusick, R.D., Logan, B.E. 2012. Phosphate recovery as struvite within a single chamber microbial electrolysis cell. Bioresource Technology, 107, 110-115.

13. Fischer, F., Bastian, C., Happe, M., Mabillard, E., Schmidt, N. 2011. Microbial fuel cell enables phosphate recovery from digested sewage sludge as struvite. Bioresource Technology, 102(10), 5824-5830.

14. Frison, N., Katsou, E., Malamis, S., Oehmen, A., Fatone, F. 2015. Nutrient removal via nitrite from reject water and polyhydroxyalkanoate (PHA) storage during nitrifying conditions. Journal of Chemical Technology and Biotechnology, 90(10), 1802-1810.

15. Gebremariam, S.Y., Beutel, M.W., Christian, D., Hess, T.F. 2012. Effects of glucose on the performance of enhanced biological phosphorus removal activated sludge enriched with acetate. Bioresource Technology, 121, 19-24.

16. Gebremariam, S.Y., Beutel, M.W., Christian, D., Hess, T.F. 2011. Research advances and challenges in the microbiology of enhanced biological phosphorus removal-a critical review. Water Environment Research, 83(3), 195-219.

17. Geerts, S., Marchi, A., Weemaes, M. 2015. Full-scale phosphorus recovery from digested wastewater sludge in Belgium-part II: economic opportunities and risks. Water Science and Technology, 71(4), 495-502.

18. Gu, A.Z., Saunders, A., Neethling, J., Stensel, H., Blackall, L. 2008. Functionally relevant microorganisms to enhanced biological phosphorus 
removal performance at full-scale wastewater treatment plants in the United States. Water Environment Research, 80(8), 688-698.

19. Hao, X., Yi, L., Fu, K. 2013. Modeling and experimental study on enhancing effect of BNR by phosphate recovery in side-stream of anaerobic supernatant. Chinese Journal of Environmental Engineering, 7(1), 231-236.

20. Henze, M., Loosdrecht, M.C.M.v., Ekama, G.A., Brdjanovic, D. 2008. Biological wastewater treatment: principles, modelling and design. IWA publishing.

21. Hirooka, K., Ichihashi, O. 2013. Phosphorus recovery from artificial wastewater by microbial fuel cell and its effect on power generation. Bioresource Technology, 137, 368-375.

22. Hood, C.R., Randall, A.A. 2001. A biochemical hypothesis explaining the response of enhanced biological phosphorus removal biomass to organic substrates. Water Research, 35(11), 2758-2766.

23. Hu, Z., Zhang, J., Li, S., Wang, J., Zhang, T. 2011. Effect of anoxic/aerobic phase fraction on $\mathrm{N}_{2} \mathrm{O}$ emission in a sequencing batch reactor under low temperature. Bioresource Technology, 102(9), 5486-5491.

24. Huang, H., Yang, J., Li, D. 2014. Recovery and removal of ammonia-nitrogen and phosphate from swine wastewater by internal recycling of struvite chlorination product. Bioresource Technology, 172, 253-259. 
25. Ichihashi, O., Hirooka, K. 2012. Removal and recovery of phosphorus as struvite from swine wastewater using microbial fuel cell. Bioresource Technology, 114, 303-307.

26. Jaffer, Y., Clark, T., Pearce, P., Parsons, S. 2002. Potential phosphorus recovery by struvite formation. Water Research, 36(7), 1834-1842.

27. Kataki, S., West, H., Clarke, M., Baruah, D. 2016. Phosphorus recovery as struvite: Recent concerns for use of seed, alternative Mg source, nitrogen conservation and fertilizer potential. Resources, Conservation and Recycling, 107, $142-156$.

28. Kelly, P.T., He, Z. 2014. Nutrients removal and recovery in bioelectrochemical systems: a review. Bioresource Technology, 153, 351-360.

29. Lay, W.C., Zhang, Q., Zhang, J., McDougald, D., Tang, C., Wang, R., Liu, Y., Fane, A.G. 2011. Study of integration of forward osmosis and biological process: membrane performance under elevated salt environment. Desalination, 283, 123-130.

30. Lederer, J., Rechberger, H. 2010. Comparative goal-oriented assessment of conventional and alternative sewage sludge treatment options. Waste Management, 30(6), 1043-1056.

31. Li, N., Ren, N.-Q., Wang, X.-H., Kang, H. 2010. Effect of temperature on intracellular phosphorus absorption and extra-cellular phosphorus removal in EBPR process. Bioresource Technology, 101(15), 6265-6268. 
32. Liu, Y., Chen, Y., Zhou, Q. 2007. Effect of initial pH control on enhanced biological phosphorus removal from wastewater containing acetic and propionic acids. Chemosphere, 66(1), 123-129.

33. Liu, Y., Qu, H. 2016. Design and optimization of a reactive crystallization process for high purity phosphorus recovery from sewage sludge ash. Journal of Environmental Chemical Engineering, 4(2), 2155-2162.

34. Lopez-Vazquez, C.M., Oehmen, A., Hooijmans, C.M., Brdjanovic, D., Gijzen, H.J., Yuan, Z., van Loosdrecht, M.C. 2009. Modeling the PAO-GAO competition: effects of carbon source, $\mathrm{pH}$ and temperature. Water Research, 43(2), 450-462.

35. Lopez-Vazquez, C.M., Song, Y.I., Hooijmans, C.M., Brdjanovic, D., Moussa, M.S., Gijzen, H.J., van Loosdrecht, M. 2007. Short - term temperature effects on the anaerobic metabolism of glycogen accumulating organisms. Biotechnology and Bioengineering, 97(3), 483-495.

36. Luo, W., Hai, F.I., Price, W.E., Guo, W., Ngo, H.H., Yamamoto, K., Nghiem, L.D. 2016. Phosphorus and water recovery by a novel osmotic membrane bioreactor-reverse osmosis system. Bioresource Technology, 200, 297-304.

37. Marbelia, L., Bilad, M.R., Passaris, I., Discart, V., Vandamme, D., Beuckels, A., Muylaert, K., Vankelecom, I.F. 2014. Membrane photobioreactors for integrated microalgae cultivation and nutrient remediation of membrane bioreactors effluent. Bioresource Technology, 163, 228-235. 
38. Marchi, A., Geerts, S., Weemaes, M., Wim, S., Christine, V. 2015. Full-scale phosphorus recovery from digested waste water sludge in Belgium-part I: technical achievements and challenges. Water Science and Technology, 71(4), 487-494.

39. Mino, T., Van Loosdrecht, M., Heijnen, J. 1998. Microbiology and biochemistry of the enhanced biological phosphate removal process. Water Research, 32(11), 3193-3207.

40. Molinos-Senante, M., Hernández-Sancho, F., Sala-Garrido, R., Garrido-Baserba, M. 2011. Economic feasibility study for phosphorus recovery processes. Ambio, 40(4), 408-416.

41. Montag, D., Gethke, K., Pinnekamp, J. 2009. Different strategies for recovering phosphorus: Technologies and costs. International Conference on nutrient recovery from waste water streams. Vancouver, Canada. IWA Publishing, London. pp. 159-167.

42. Mulkerrins, D., O’Connor, E., Lawlee, B., Barton, P., Dobson, A. 2004. Assessing the feasibility of achieving biological nutrient removal from wastewater at an Irish food processing factory. Bioresource Technology, 91(2), 207-214.

43. Naessens, W., Maere, T., Nopens, I. 2012. Critical review of membrane bioreactor models-Part 1: Biokinetic and filtration models. Bioresource Technology, 122, 95-106. 
44. Ong, Y.H., Chua, A.S.M., Fukushima, T., Ngoh, G.C., Shoji, T., Michinaka, A. 2014. High-temperature EBPR process: The performance, analysis of PAOs and GAOs and the fine-scale population study of Candidatus "Accumulibacter phosphatis”. Water Research, 64, 102-112.

45. P-bac. 2013. Vol. 2015. http://fritzmeier-umwelttechnik.com/p-bac-process/?lang=en.

46. Pratt, C., Parsons, S.A., Soares, A., Martin, B.D. 2012. Biologically and chemically mediated adsorption and precipitation of phosphorus from wastewater. Current Opinion in Biotechnology, 23(6), 890-896.

47. Qiu, G., Law, Y.-M., Das, S., Ting, Y.-P. 2015. Direct and complete phosphorus recovery from municipal wastewater using a hybrid microfiltration-forward osmosis membrane bioreactor process with seawater brine as draw solution. Environmental Science and Technology, 49(10), 6156-6163.

48. Qiu, G., Ting, Y.-P. 2014a. Direct phosphorus recovery from municipal wastewater via osmotic membrane bioreactor (OMBR) for wastewater treatment. Bioresource Technology, 170, 221-229.

49. Qiu, G., Ting, Y.-P. 2014b. Short-term fouling propensity and flux behavior in an osmotic membrane bioreactor for wastewater treatment. Desalination, 332(1), 91-99.

50. Sairam, M., Sereewatthanawut, E., Li, K., Bismarck, A., Livingston, A. 2011. Method for the preparation of cellulose acetate flat sheet composite membranes 
for forward osmosis-desalination using MgSO 4 draw solution. Desalination, 273(2), 299-307.

51. Sarlin, T.H., Priha, O.K., Arnold, M.E., Kinnunen, P.H. 2013. Bioleaching of phosphorus from low grade ores and concentrates with acidophilic iron-and sulphur-oxidizing bacteria. Advanced Materials Research. Trans Tech Publ. pp. 266-269.

52. Sartorius, C., von Horn, J., Tettenborn, F. 2012. Phosphorus recovery from wastewater-Expert survey on present use and future potential. Water Environment Research, 84(4), 313-322.

53. Schoumans, O.F., Bouraoui, F., Kabbe, C., Oenema, O., van Dijk, K.C. 2015. Phosphorus management in Europe in a changing world. Ambio, 44(2), 180-192.

54. Shepherd, J.G., Sohi, S.P., Heal, K.V. 2016. Optimising the recovery and re-use of phosphorus from wastewater effluent for sustainable fertiliser development. Water Research, 94, 155-165.

55. Shi, J., Lu, X., Yu, R., Zhu, W. 2012. Nutrient removal and phosphorus recovery performances of a novel anaerobic-anoxic/nitrifying/induced crystallization process. Bioresource Technology, 121, 183-189.

56. Tao, Q., Luo, J., Zhou, J., Zhou, S., Liu, G., Zhang, R. 2014. Effect of dissolved oxygen on nitrogen and phosphorus removal and electricity production in microbial fuel cell. Bioresource Technology, 164, 402-407. 
57. Tarayre, C., De Clercq, L., Charlier, R., Michels, E., Meers, E., Camargo-Valero, M., Delvigne, F. 2016. New perspectives for the design of sustainable bioprocesses for phosphorus recovery from waste. Bioresource Technology, 206, 264-274.

58. Tayà, C., Guisasola, A., Baeza, J.A. 2011. Assessment of a bioaugmentation strategy with polyphosphate accumulating organisms in a nitrification/denitrification sequencing batch reactor. Bioresource Technology, 102(17), 7678-7684.

59. Tian, Y., Lu, Y., Li, Z. 2012. Performance analysis of a combined system of membrane bioreactor and worm reactor: wastewater treatment, sludge reduction and membrane fouling. Bioresource Technology, 121, 176-182.

60. Verstraete, W., Van de Caveye, P., Diamantis, V. 2009. Maximum use of resources present in domestic "used water". Bioresource Technology, 100(23), $5537-5545$.

61. Wang, D., Zheng, W., Liao, D., Li, X., Yang, Q., Zeng, G. 2013. Effect of initial $\mathrm{pH}$ control on biological phosphorus removal induced by the aerobic/extended-idle regime. Chemosphere, 90(8), 2279-2287.

62. Wang, G., Sui, J., Shen, H., Liang, S., He, X., Zhang, M., Xie, Y., Li, L., Hu, Y. 2011a. Reduction of excess sludge production in sequencing batch reactor through incorporation of chlorine dioxide oxidation. Journal of Hazardous Materials, 192(1), 93-98. 
63. Wang, Q., Chen, Q. 2015. Simultaneous denitrification and denitrifying phosphorus removal in a full-scale anoxic-oxic process without internal recycle treating low strength wastewater. Journal of Environmental Sciences, 39(1), $175-183$.

64. Wang, X., Yuan, B., Chen, Y., Li, X., Ren, Y. 2014. Integration of micro-filtration into osmotic membrane bioreactors to prevent salinity build-up. Bioresource Technology, 167, 116-123.

65. Wang, Y., Geng, J., Ren, Z., He, W., Xing, M., Wu, M., Chen, S. 2011b. Effect of anaerobic reaction time on denitrifying phosphorus removal and $\mathrm{N}_{2} \mathrm{O}$ production. Bioresource Technology, 102(10), 5674-5684.

66. Wang, Y., Jiang, F., Zhang, Z., Xing, M., Lu, Z., Wu, M., Yang, J., Peng, Y. 2010. The long-term effect of carbon source on the competition between polyphosphorus accumulating organisms and glycogen accumulating organism in a continuous plug-flow anaerobic/aerobic $(\mathrm{A} / \mathrm{O})$ process. Bioresource Technology, 101(1), 98-104.

67. Wang, Z., Meng, Y., Fan, T., Du, Y., Tang, J., Fan, S. 2015. Phosphorus removal and $\mathrm{N}_{2} \mathrm{O}$ production in anaerobic/anoxic denitrifying phosphorus removal process: Long-term impact of influent phosphorus concentration. Bioresource Technology, 179, 585-594. 
68. Winkler, M., Coats, E.R., Brinkman, C.K. 2011. Advancing post-anoxic denitrification for biological nutrient removal. Water Research, 45(18), 6119-6130.

69. Wong, P.Y., Cheng, K.Y., Kaksonen, A.H., Sutton, D.C., Ginige, M.P. 2013. A novel post denitrification configuration for phosphorus recovery using polyphosphate accumulating organisms. Water Research, 47(17), 6488-6495.

70. Xie, C., Zhao, J., Tang, J., Xu, J., Lin, X., Xu, X. 2011. The phosphorus fractions and alkaline phosphatase activities in sludge. Bioresource Technology, 102(3), 2455-2461.

71. Xie, E., Xu, X., Luo, G. 2013. Study on a novel reactor of sludge process reduction for domestic sewage treatment. Environmental Technology, 34(12), 1593-1599.

72. Yan, P., Guo, J.-S., Wang, J., Chen, Y.-P., Ji, F.-Y., Dong, Y., Zhang, H., Ouyang, W.-j. 2015. Enhanced nitrogen and phosphorus removal by an advanced simultaneous sludge reduction, inorganic solids separation, phosphorus recovery, and enhanced nutrient removal wastewater treatment process. Bioresource Technology, 183, 181-187.

73. Yan, P., Ji, F., Wang, J., Fan, J., Guan, W., Chen, Q. 2013. Pilot-scale test of an advanced, integrated wastewater treatment process with sludge reduction, inorganic solids separation, phosphorus recovery, and enhanced nutrient removal (SIPER). Bioresource Technology, 142C(4), 483-489. 
74. Yap, W.J., Zhang, J., Lay, W.C., Cao, B., Fane, A.G., Liu, Y. 2012. State of the art of osmotic membrane bioreactors for water reclamation. Bioresource Technology, 122, 217-222.

75. Ye, L., Pijuan, M., Yuan, Z. 2013. The effect of free nitrous acid on key anaerobic processes in enhanced biological phosphorus removal systems. Bioresource Technology, 130, 382-389.

76. Yu, S., Sun, P., Zheng, W., Chen, L., Zheng, X., Han, J., Yan, T. 2014. The effect of COD loading on the granule-based enhanced biological phosphorus removal system and the recoverability. Bioresource Technology, 171, 80-87.

77. Yuan, Z., Pratt, S., Batstone, D.J. 2012. Phosphorus recovery from wastewater through microbial processes. Current Opinion in Biotechnology, 23(6), 878-883.

78. Zeng, W., Wang, X., Li, B., Bai, X., Peng, Y. 2013. Nitritation and denitrifying phosphorus removal via nitrite pathway from domestic wastewater in a continuous MUCT process. Bioresource Technology, 143(9), 187-195.

79. Zeng, W., Yang, Y., Li, L., Wang, X., Peng, Y. 2011. Effect of nitrite from nitritation on biological phosphorus removal in a sequencing batch reactor treating domestic wastewater. Bioresource Technology, 102(12), 6657-6664.

80. Zengin, G.E., Artan, N., Orhon, D., Chua, A.S., Satoh, H., Mino, T. 2010. Population dynamics in a sequencing batch reactor fed with glucose and operated for enhanced biological phosphorus removal. Bioresource Technology, 101(11), 4000-4005. 
81. Zhang, F., Li, J., He, Z. 2014. A new method for nutrients removal and recovery from wastewater using a bioelectrochemical system. Bioresource Technology, 166, 630-634.

82. Zhang, Z., Li, H., Zhu, J., Weiping, L., Xin, X. 2011. Improvement strategy on enhanced biological phosphorus removal for municipal wastewater treatment plants: Full-scale operating parameters, sludge activities, and microbial features. Bioresource Technology, 102(7), 4646-4653.

83. Zhao, F., Harnisch, F., Schröder, U., Scholz, F., Bogdanoff, P., Herrmann, I. 2006. Challenges and constraints of using oxygen cathodes in microbial fuel cells. Environmental Science and Technology, 40(17), 5193-5199.

84. Zheng, X., Sun, P., Han, J., Song, Y., Hu, Z., Fan, H., Lv, S. 2014. Inhibitory factors affecting the process of enhanced biological phosphorus removal (EBPR)-A mini-review. Process Biochemistry, 49(12), 2207-2213.

85. Zhou, Y., Pijuan, M., Oehmen, A., Yuan, Z. 2010. The source of reducing power in the anaerobic metabolism of polyphosphate accumulating organisms (PAOs)-A mini-review. Water Science and Technology, 61(7), 1653.

86. Zou, H., Wang, Y. 2016. Phosphorus removal and recovery from domestic wastewater in a novel process of enhanced biological phosphorus removal coupled with crystallization. Bioresource Technology, 211, 87-92. 
87. Zuthi, M., Guo, W., Ngo, H., Nghiem, L., Hai, F. 2013. Enhanced biological

phosphorus removal and its modeling for the activated sludge and membrane bioreactor processes. Bioresource Technology, 139, 363-374. 


\section{Figure captions}

Fig. 1 Various potential spots for nutrient recovery in sewage treatment (modified from Cornel and Schaum, 2009). A, B and C present the potential process steps where nutrient recovery from the liquid phase could be carried out, while the numbers (i.e. 1 and 2) indicate where mean nutrient recovery from the sludge phase could take place. A: anaerobic digestion supernatant; B: reject water; C: sludge dewatering filtrate; 1 : dry/dewatered sewage sludge; and 2: sewage sludge ash through incineration of sewage sludge.

Fig. 2 The mechanism of $\mathrm{P}$ recovery via biological process (modified from Wong et al., 2013). The anaerobic behaviours of PAOs include: carbon source uptake, storage of PHAs, P release, hydrolysis of polyp and glycolysis of glycogen while the aerobic/anoxic behaviours of PAOs consist of: biomass growth, utilize of PHAs, glycogen synthesis, P uptake and polyp synthesis. PAOs: polyphosphorus accumulating organisms; PHA: poly- $\beta$-hydroxyalkanoates; PolyP: Polyphosphate.

Fig. 3 Diagram of the SIPER process (adapted from Yan et al., 2013). In the SIPER process, the biological nutrient removal is combined with chemical precipitation to achieve more efficient nutrient recovery with less operational costs since the treated sludge could be returned as the carbon source. (i), (ii), (iii) and (iv) represent biological nutrient removal system, a side-stream enhanced sludge hydrolysis and acidification 
system, side-stream inorganic solids separation system and side-stream phosphorus recovery system, respectively. A, B and C present bio-selector, anaerobic zone, and aerobic zone, respectively. 


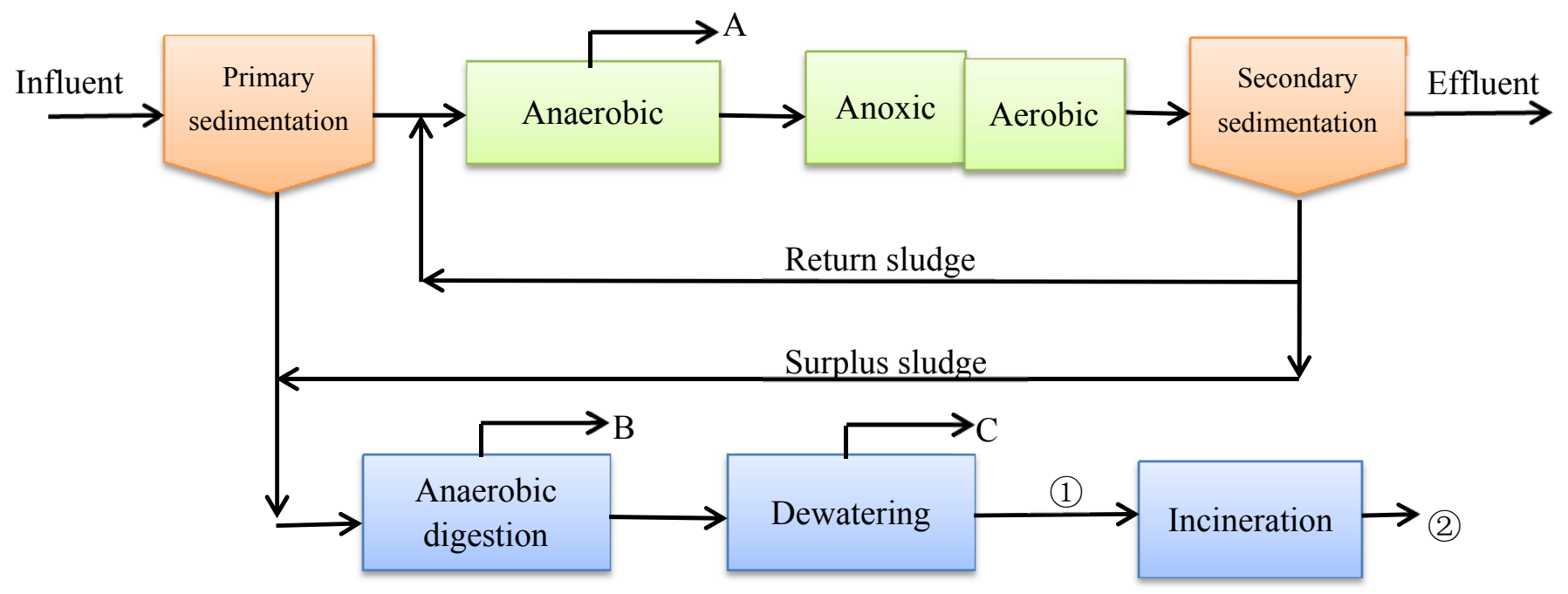

Fig. 1 


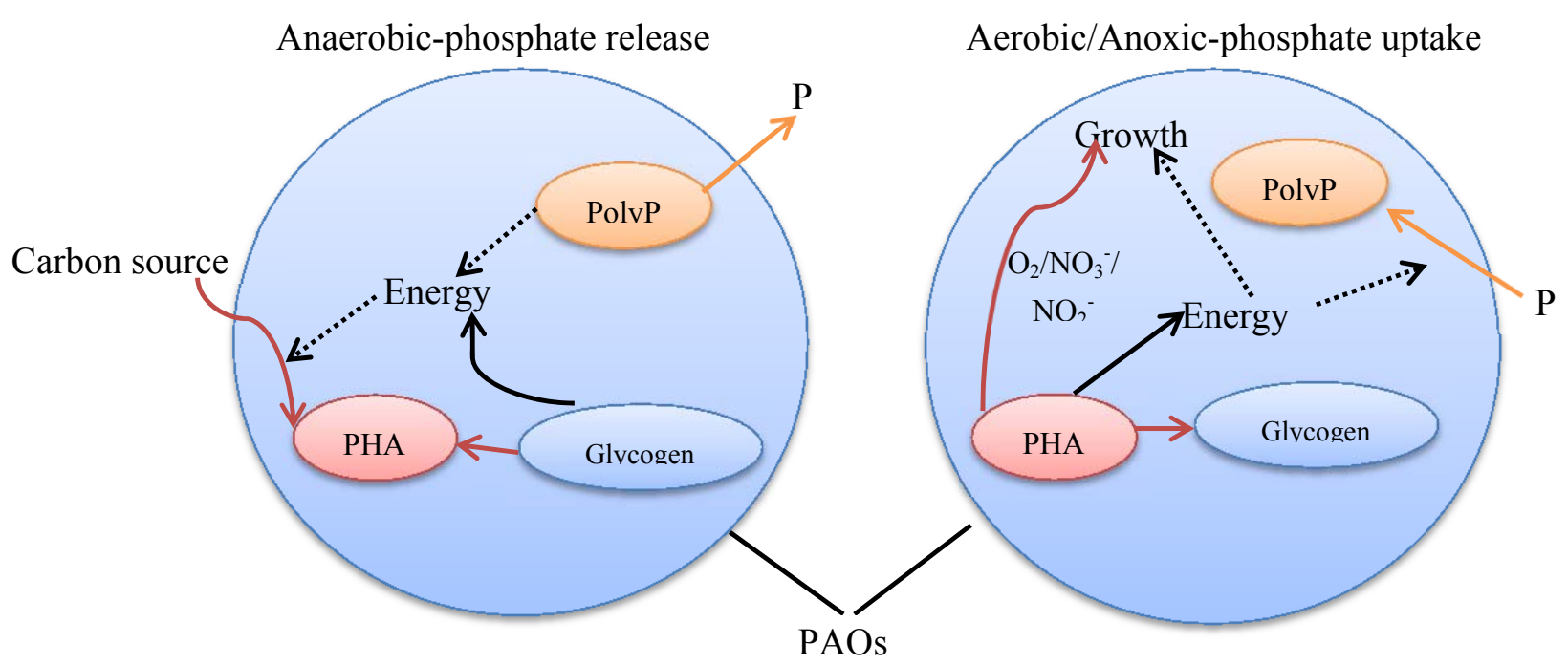

Fig. 2 


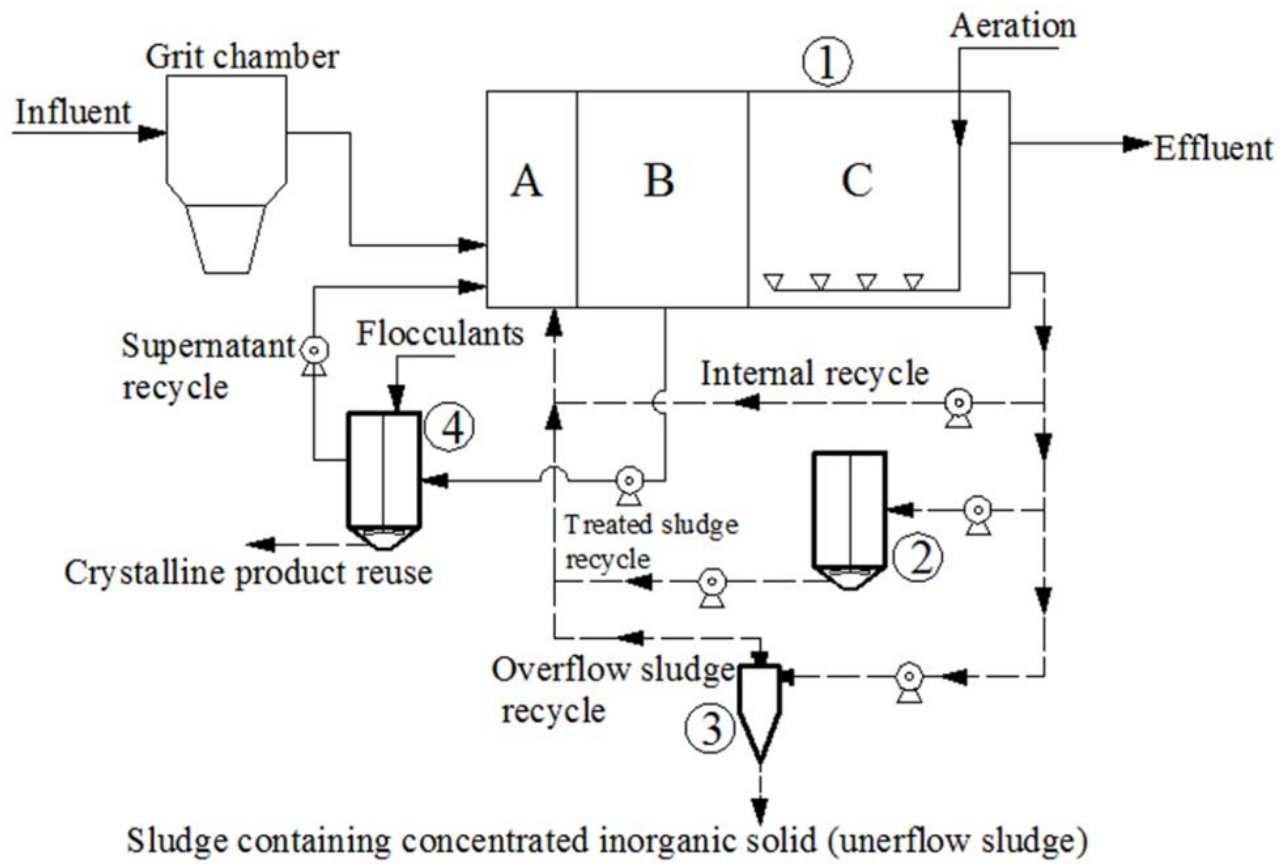

Fig. 3 
Table 1 Effects of operating parameters on phosphate recovery

\begin{tabular}{|c|c|c|}
\hline $\begin{array}{l}\text { Operating } \\
\text { parameters }\end{array}$ & $\begin{array}{l}\text { Effects on phosphate } \\
\text { recovery }\end{array}$ & References \\
\hline \multirow[t]{5}{*}{ Temperature } & Low temperature facilitate & Bassin et al. (2012), \\
\hline & the phosphate recovery & Lopez-Vazquez et al. (2007), \\
\hline & & Gebremariam et al. (2011), Wang \\
\hline & & and Chen (2015), Zheng et al. \\
\hline & & (2014) \\
\hline \multirow[t]{3}{*}{$\mathrm{pH}$} & Existing controversy & Gebremariam et al. (2011), Wang \\
\hline & & et al. (2013), Liu et al. (2007), Gu \\
\hline & & et al. (2008) \\
\hline Carbon availability & High concentration of & Chuang et al. (2011), Zhang et al. \\
\hline \multirow[t]{2}{*}{ and type } & carbon source contribute to & (2011), \\
\hline & the phosphate recovery & \\
\hline \multirow[t]{3}{*}{ Dissolved oxygen } & Low DO concentration & Winkler et al. (2011), Chen et al. \\
\hline & facilitate the phosphate & (2014), Carvalheira et al. (2014) \\
\hline & recovery & \\
\hline
\end{tabular}

